\title{
Improvement of survival for non-small cell lung cancer over time
}

\author{
Wenjie Xia ${ }^{1-3, *}$ \\ Xinnian $\mathrm{Yu}^{4, *}$ \\ Qixing $\mathrm{Mao}^{1-3, *}$ \\ Wenying $\mathrm{Xia}^{5}$ \\ Anpeng Wang ${ }^{1-3}$ \\ Gaochao Dong ${ }^{1,2}$ \\ Bing Chen ${ }^{1-3}$ \\ Weidong $\mathrm{Ma}^{1-3}$ \\ Lin $X u^{1,2}$ \\ Feng Jiang ${ }^{1,2}$ \\ 'Department of Thoracic Surgery, \\ Nanjing Medical University \\ Affiliated Cancer Hospital; ${ }^{2}$ jiangsu \\ Key Laboratory of Molecular and \\ Translational Cancer Research, \\ Cancer Institute of Jiangsu Province, \\ ${ }^{3}$ The Fourth Clinical College \\ of Nanjing Medical University, \\ ${ }^{4}$ Department of Chemotherapy, \\ Nanjing Medical University Affiliated \\ Cancer Hospital Cancer Institute \\ of Jiangsu Province, ${ }^{5}$ Department \\ of Laboratory Medicine, the First \\ Affiliated Hospital of Nanjing Medical \\ University, Nanjing, China \\ *These authors contributed equally \\ to this work
}

Correspondence: Lin Xu; Feng Jiang jiangsu Key Laboratory of Molecular and Translational Cancer Research, Cancer Institute of Jiangsu Province, Baiziting 42, Nanjing 210009, China

Tel +86258328 4700; +862583283408

Fax +86258364I062

Email xulin_83@hotmail.com; zengnljf@hotmail.com
This article was published in the following Dove Press journal:

OncoTargets and Therapy

29 August 2017

Number of times this article has been viewed

Abstract: Non-small cell lung cancer (NSCLC) is the main histological subtype of lung cancer, which is the leading cause of cancer death. It is unclear whether the improved survival seen at high-volume centers applies to the general population and, more importantly, whether the improvement in lung cancer survival was just a consequence of improved screening work. Data from the Surveillance, Epidemiology, and End Results (SEER) registry was used to identify 405,580 patients with NSCLC diagnosed from 1988 to 2008. The patients were divided into four groups according to the year of diagnosis. Trends of clinical characteristics were analyzed to reflect the progress of screening work. Five-year relative survivals in various subgroups were compared. The results indicated that proportion of aged, advanced, and non-surgical patients increased, whereas patients with lymph node metastasis and high histology grade decreased. Improvements in all stages of NSCLC patients were demonstrated, with relatively more significant gains for patients with localized and regional disease. After potentially curative surgical resection, remarkable improvements were observed in both cohorts with time (surgical: $52.00 \%-63.00 \%$; non-surgical: 6.10\%-13.50\%). Specifically, patients who underwent pneumonectomy, lobectomy/bilobectomy, and partial/wedge/segmental resection all presented better survival rates. Our SEER analysis demonstrated improvements among patients in all stages of NSCLC that were deemed attributable to improved therapy and medical care for NSCLC rather than improved screening work.

Keywords: NSCLC, survival, SEER, screening, surgery

\section{Introduction}

Lung cancer is the leading cause of cancer death, with more than one-quarter $(27 \%)$ of all cancer deaths due to lung cancer. ${ }^{1}$ The main histological subtype of lung cancer is non-small-cell lung cancer (NSCLC), which accounts for $85 \%$ of cases and includes adenocarcinoma, squamous cell carcinoma, and large cell carcinoma. ${ }^{2}$ Results obtained from some high-volume centers showed decreased hospital costs and improved shortand long-term surgical outcomes after complex surgery. ${ }^{3-6}$ However, it is unclear whether this improved survival seen at high-volume centers applied to the general population on account of the gaps in the quality of medical care.

Lung cancer screening was expected to usher in a new era of early diagnosis and treatment, leading to better survival for the overall population of patients with lung cancer. ${ }^{7}$ If the progress of screening work, indeed, contributed to the better NSCLC outcomes, the improved survival reflected by the increasing proportion of early-stage patients may lead to an appearance of improved medical therapy. It is important to know whether the improvement in lung cancer survival (if it truly existed) was attributable to changes in diagnostic or disease factors. 
In this study, we used the Surveillance, Epidemiology, and End Results (SEER) data set to investigate the changes in presentation and survival statistics in NSCLC over the last two decades.

\section{Materials and methods}

Data from the Surveillance, Epidemiology, and End Results (SEER) registry was used to identify 405,580 patients with NSCLC diagnosed from 1988 to 2008. The SEER Program currently collects and publishes cancer incidence and survival data from population-based cancer registries covering approximately $30 \%$ of the US population. ${ }^{8}$ The following criteria were applied to identify all eligible cases: 1) tumor with malignant behavior located in "Lung and Bronchus" (ICD-O-3/WHO 2008 site code C340-C343,C348-C349); ${ }^{9}$ 2) tumor diagnosis between January 1,1988 and December 31 , 2008, (patients diagnosed before 1988 were excluded because there was no SEER data available on information of summary stage, patients diagnosed after 2008 were eliminated to ensure that we had adequate follow-up to evaluate 5-year survival); 3 ) patients diagnosed by autopsy or reported only on a death certificate were excluded; and 4) the analysis included only patients with NSCLC. Therefore, patients with small cell carcinoma, sarcoma, lymphoma, or uncertain histologic types were eliminated.

Demographic and clinicopathological parameters were extracted using the "case listing" option. Cases were stratified by sex, race, age at diagnosis, year of diagnosis, whether accepted surgery, regional lymph node status, tumor grade, and SEER summary stage, which is derived from the Collaborative Stage (CS) for patients diagnosed after 2004 and the extent of disease (EOD) for patients from 1973 to 2003. It is a simplified version of stage: localized, regional, distant, and unknown. Data on 5-year relative survival were collected using the survival sessions available in SEER *Stat version 8.3.2. Relative survival is defined as the ratio of the proportion of observed survivors (all causes of death) in a cohort of cancer patients to the proportion of expected survivors in a comparable cohort of cancer-free individuals. Observational survival data also available as the survival variable in the SEER database represents the number of months from cancer diagnosis to the date of death. All patients were adequately followed-up at the time of study cut-off (December 31, 2013). Kaplan-Meier curves were generated to determine median and 5-year survival rates, and the log-rank test was employed to undertake comparisons of survival between different groups. Chi-square analysis was used to compare proportions for all categorical data. When evaluating trends, $P$-values from the Cochran-Armitage trend test were reported. All statistical analyses were conducted with the SPSS v.19 statistical package. Significance was accepted at the $P<0.05$ level.

\section{Results}

\section{Trends of clinical characteristics indicated the stagnation of screening work}

From 1988 to 2008 , there were 405,580 patients with histologically confirmed NSCLC who met the inclusion criteria. The distribution of diagnosis year was statistically different across all demographic and clinicopathological characteristics as all $P$-values from the chi-square analysis test were less than 0.001 (Table 1).

The development of screening work can be indicated by average age, stage, and differentiated degree at diagnosis. However, the trends of different characteristics over the 20 -year study period were inconsistent. The prevalence seemed to trend toward the aging population as the proportion of patients in the youngest group $(<50$ years $)$ decreased steadily from $7.64 \%$ to $6.61 \%$, whereas the oldest group (>80 years) increased from $9.26 \%$ to $15.3 \%$; mean age at diagnosis also rose from 65.61 to 67.87 (Table 1, Figure 1A). Meanwhile, patients who presented with staging as distant increased from $45.07 \%$ to $55.05 \%$ and the proportion of localized and regional patients declined from $45.26 \%$ to $41.43 \%$ (Table 1, Figure 1B). These findings seemed to indicate that we did not make progress in screening patients with NSCLC, but tended to retrogress during the 20-year study period.

On the contrary, the percentage of patients with lymph node metastasis decreased (from $13.97 \%$ to $11.98 \%$ ) and the percentage without lymph node metastasis increased (from $15.68 \%$ to $17.3 \%$ ). Rates of high-grade NSCLC also dropped (Grade III from $35.61 \%$ to $29.09 \%$, Grade IV from $8.66 \%$ to $2.72 \%$ ) whereas the percentage of patients with Grades I and II staging were fairly constant $(4.01 \%-4.7 \%$, $15.00 \%-16.51 \%$, respectively), which could be best understood when looking at Figure $1 \mathrm{C}$ and D. However, these findings were inadequate to support the progress of screening efforts.

Besides, irrelevant to the uncertain screening work status, with time, females made up a clearly increasingly larger proportion of the NSCLC population (37.18\%-45.29\%) whereas the proportion of patients presenting with squamous cell carcinoma became smaller (31.1\%-23.3\%, Figure $1 \mathrm{E}$ and F).

\section{Survival analysis for overall and specific stages of patients}

We then evaluated trends in survival over time; despite the uncertain screening status, survival had increased steadily 
Table I Demographic and clinicopathological characteristics of patients with NSCLC

\begin{tabular}{|c|c|c|c|c|c|c|}
\hline \multirow[t]{2}{*}{ Characteristics } & \multirow{2}{*}{$\begin{array}{l}\text { Total number } \\
\mathrm{N}=\mathbf{4 0 5 , 5 8 0} \\
\mathrm{n}(\%)\end{array}$} & \multicolumn{4}{|l|}{ Year of diagnosis } & \multirow[t]{2}{*}{$P$-value } \\
\hline & & $\begin{array}{l}1988-1992 \\
n=50,035, n(\%)\end{array}$ & $\begin{array}{l}1993-1997 \\
n=64,179, \text { n (\%) }\end{array}$ & $\begin{array}{l}1998-2002 \\
n=I \mid 5,163, n(\%)\end{array}$ & $\begin{array}{l}2002-2008 \\
n=176,203, n(\%)\end{array}$ & \\
\hline Ages $($ median $=68)$ & & & & & & $<0.001$ \\
\hline$<50$ & 28,351 (6.99) & 7.64 & 7.28 & 7.13 & 6.61 & \\
\hline $50-59$ & $69,609(17.16)$ & 17.38 & 16.49 & 17.3 & 17.26 & \\
\hline $60-69$ & $123,926(30.56)$ & 35.46 & 31.94 & 29.15 & 29.58 & \\
\hline $70-79$ & $129,533(31.94)$ & 30.26 & 33.02 & 33.09 & 31.26 & \\
\hline$>80$ & $54,161(13.35)$ & 9.26 & 11.27 & 13.33 & 15.3 & \\
\hline Sex & & & & & & $<0.001$ \\
\hline Male & 231,101 (56.98) & 62.82 & 58.84 & 56.88 & 54.71 & \\
\hline Female & $174,479(43.02)$ & 37.18 & 41.16 & 43.12 & 45.29 & \\
\hline Race & & & & & & $<0.001$ \\
\hline White & $331,360(81.70)$ & 82.82 & 80.6 & 82.15 & 81.49 & \\
\hline Black & 47,417 (11.69) & 11.61 & 11.85 & 11.53 & 11.76 & \\
\hline Other & $26,152(6.45)$ & 5.51 & 7.42 & 6.16 & 6.55 & \\
\hline Unknown & $65 I(0.16)$ & 0.06 & 0.13 & 0.15 & 0.2 & \\
\hline Summary stage & & & & & & $<0.001$ \\
\hline Localized & $7 \mid, 822(|7.7|)$ & 17.97 & 18.09 & 17.33 & 17.74 & \\
\hline Regional & $101,239(24.96)$ & 27.29 & 27.73 & 24.35 & 23.69 & \\
\hline Distant & $209,506(51.66)$ & 45.07 & 46.84 & 52.01 & 55.05 & \\
\hline Unstaged & $23,013(5.67)$ & 9.67 & 7.33 & 6.31 & 3.52 & \\
\hline Surgery & & & & & & $<0.001$ \\
\hline No & 295,978 (72.98) & 72.03 & 72.34 & 73.18 & 73.34 & \\
\hline Yes & $107,268(26.45)$ & 27.82 & 27.42 & 26.1 & 25.93 & \\
\hline Unknown & $2,334(0.58)$ & 0.15 & 0.23 & 0.73 & 0.72 & \\
\hline LN status & & & & & & $<0.001$ \\
\hline Negative & $67,040(16.53)$ & 15.68 & 15.26 & 16.43 & 17.3 & \\
\hline Positive & $50,921(12.56)$ & 13.97 & 13.14 & 12.49 & 11.98 & \\
\hline No nodes examined & $279,381(68.88)$ & 68.32 & 70.43 & 68.76 & 68.56 & \\
\hline Unknown & $8,238(2.03)$ & 2.03 & 1.17 & 2.32 & 2.15 & \\
\hline Grade & & & & & & $<0.001$ \\
\hline I & I7,667 (4.36) & 4.01 & 4.14 & 4.09 & 4.7 & \\
\hline ॥ & 64,574 (I5.92) & 15.00 & 15.49 & 15.67 & 16.51 & \\
\hline III & 129,877 (32.02) & 35.60 & 36.87 & 32.24 & 29.09 & \\
\hline IV & $18,962(34.68)$ & 8.66 & 7.28 & 4.49 & 2.72 & \\
\hline Unknown & $174,500(43.02)$ & 36.73 & 36.21 & 43.51 & 46.98 & \\
\hline Pathological type & & & & & & $<0.001$ \\
\hline Squamous cell & $|02,5| \mid(25.28)$ & 31.15 & 27.12 & 24.75 & 23.28 & \\
\hline Adenocarcinoma & $167,166(41.22)$ & 40.27 & 42.57 & 41.11 & 41.06 & \\
\hline Others or NSCLC NOS & I35,903 (33.50) & 28.58 & 30.31 & 34.14 & 35.65 & \\
\hline
\end{tabular}

Note: Chi-square analysis was used to compare proportions for all categorical data.

Abbreviations: NOS, not otherwise specified; NSCLC, non-small cell lung cancer; LN, lymph node.

over time. The median relative survival of patients with NSCLC remained less than 1 year; however, it improved from 8.69 months to 10.38 months in each lustrum. Five-year survival was then compared over the four time periods (Figure 2A). Great gains in survival over time were observed in patients with localized $(n=71,822)$ and regional $(n=101,239)$ stage disease compared to patients with distant disease $(n=209,506)$. Over the first 5 years after diagnosis, relative survival improved from $50.8 \%$ [95\% confidence interval (CI) $49.60 \%-52.00 \%$ ] to $57.00 \%$ (95\% CI 56.30\%-57.60\%) in the localized stage group; $18.70 \%$ (95\% CI $18.00 \%-19.50 \%)$ to $28.90 \%(95 \%$ CI $28.40 \%-29.40 \%$ ) in the regional stage group, and $2.0 \%$ (95\% CI $1.80 \%-2.20 \%)$ to $4.2 \%(95 \%$ CI $4.10 \%-4.40 \%)$ in the distant stage group (Figure 2B-D).

\section{Trend of surgery rate and survival analysis for surgical and non-surgical group}

To determine if surgical advancements contributed to the achievement of NSCLC survival, we also subdivided patients with localized and regional disease into surgical and non-surgical groups, because these patients are potential 

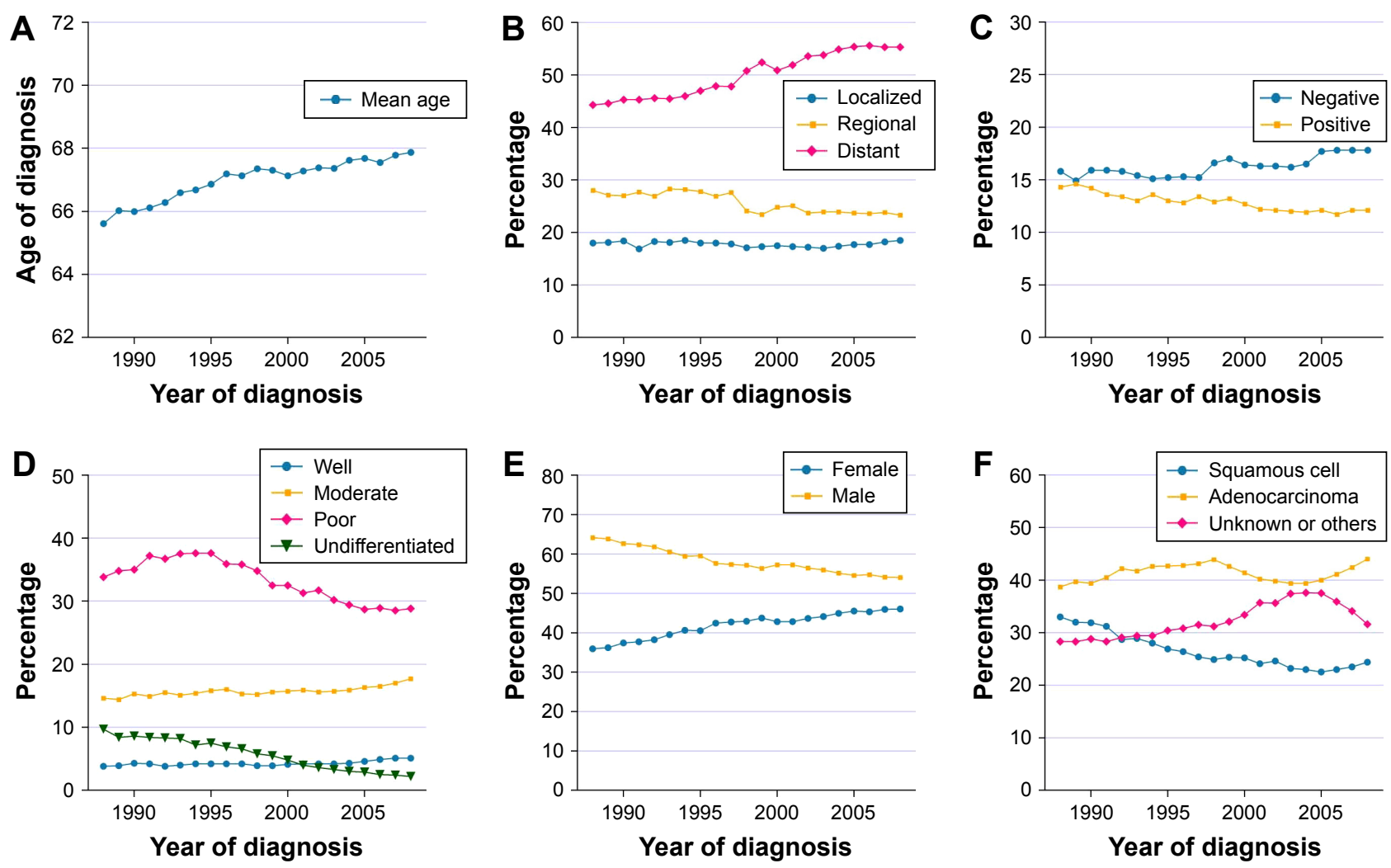

Figure I Trends of demographic and clinicopathological characteristics for NSCLC from 1988 to 2008. Sample means (A: age of diagnosis) and proportions (B: summary stage; C: lymph node metastasis; D: histological grade; E: sex; and F: pathological type) of NSCLC cases are shown by year of diagnosis. One-way ANOVA analysis (A) and Cochran-Armitage trend test $(\mathbf{B}-\mathbf{F})$ were used, all $P$-values $<0.00$ I.

candidates for surgical resection. Surgery rates remained almost unchanged (Figure 3A). After potentially curative surgical resection, as shown in Figure $3 \mathrm{~B}$ and $\mathrm{C}$, remarkable improvements were observed in both cohorts over time (surgical: 52.00\%-63.00\%; non-surgical: 6.10\%-13.50\%). This disparity in the survival rate between the surgical and non-surgical groups also embodied the mainstay role of surgery in NSCLC therapeutics.

\section{Trend of distribution of surgical approaches and survival analysis for specific surgical approaches}

Specific to different methods of surgeries, it is not surprising that the proportion of patients who accepted partial/wedge/ segmental resection among all patients who underwent surgery experienced an increase from $11.9 \%$ to $16.8 \%$. Patients who underwent pneumonectomy decreased from $14.3 \%$ to $5.6 \%$, which might be attributed to the increasingly diversified treatment choices, as patients, after pneumonectomy, had to bear a poor quality of life. The percentage of patients who underwent lobectomy/bilobectomy, which accounted for the major part of surgical patients, remained relatively stable, ranging approximately 75\% (Figure 4A). Patients who underwent pneumonectomy, lobectomy/bilobectomy, and partial/wedge/segmental resection all presented better survival rate (pneumonectomy: $33.70 \%-44.10 \%$, lobectomy/ bilobectomy: $56.20 \%-66.20 \%$, partial/wedge/segmental resection: $47.20 \%-57.80 \%$, Figure 4B-E). These results indicated that all methods of surgery as therapeutic approaches demonstrated solid progress during the last two decades.

\section{Discussion}

Here, we evaluated the trends of clinical characteristics which could indicate the progress of screening work and analyzed survivals for NSCLC over the last two decades. There were improvements in all stages of NSCLC, with more significant gains observed for patients with localized and regional diseases. Furthermore, we demonstrated a significant increase in survival for patients through major surgical approaches. Based on the aforementioned evidence, it is unlikely that the improvement in survival was attributable to progressing screening work.

Advances in screening of disease are distorting physicians' perceptions of the natural history of diseases and 

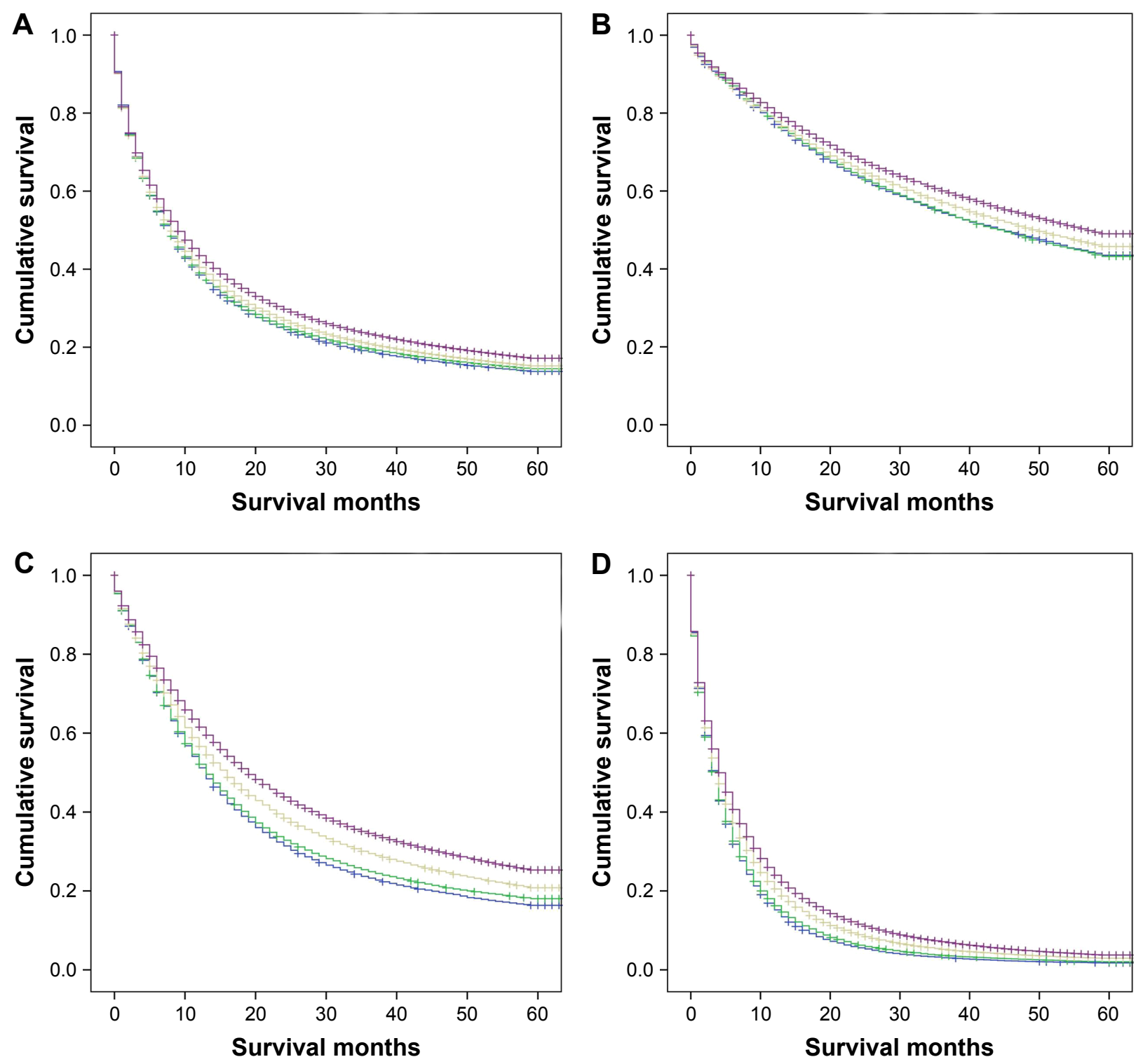

$$
\neg \text { 1988-1992 } \neg \text { 1993-1997 } \neg \text { 1998-2002 } \neg \text { 2003-2008 }
$$

Figure 2 Kaplan-Meier survival analysis for overall (A) and specific stages of patients: (B) Localized, (C) Regional, and (D) Distant, with NSCLC between I988 and 2008 grouped by periods of diagnosis. All $P$-values $<0.00 \mathrm{I}$.

causing overestimations of benefits of therapy. ${ }^{10,11}$ However, such concerns are redundant in the case of NSCLC due to the little effect that screening work generated on improved survivals, as reflected from the evidence in the present study.

The work of NSCLC screening had experienced a difficult period. Although chest X-ray (CXR) had been deemed as a potential lung cancer screening test for decades, it did not show a benefit in reducing lung cancer mortality in randomized controlled trials conducted in the 1960s-1980s. ${ }^{12-17}$ Several observational studies revealed that low-dose CT (LDCT) of the lung could detect more potential positive nodules and lung cancers, including early-stage cancers, than does CXR. ${ }^{18,19}$ In 2011, the National Lung Screening Trial (NLST), a combination of two randomized controlled trials of 53,454 people enrolled for comparing LDCT with CXR, reported a 20\% lung cancer-specific mortality reduction, as well as an overall mortality reduction of $6.7 \%$ in a high-risk cohort screened with annual LDCT for 2 years. ${ }^{7}$ Roughly based on this study, several professional organizations, including the National Comprehensive Cancer Network (NCCN), the American College of Chest Physicians (ACCP), the American Cancer Society (ACS), the American Lung Association (ALA), the American Society of Clinical Oncology (ASCO), and the American Association 

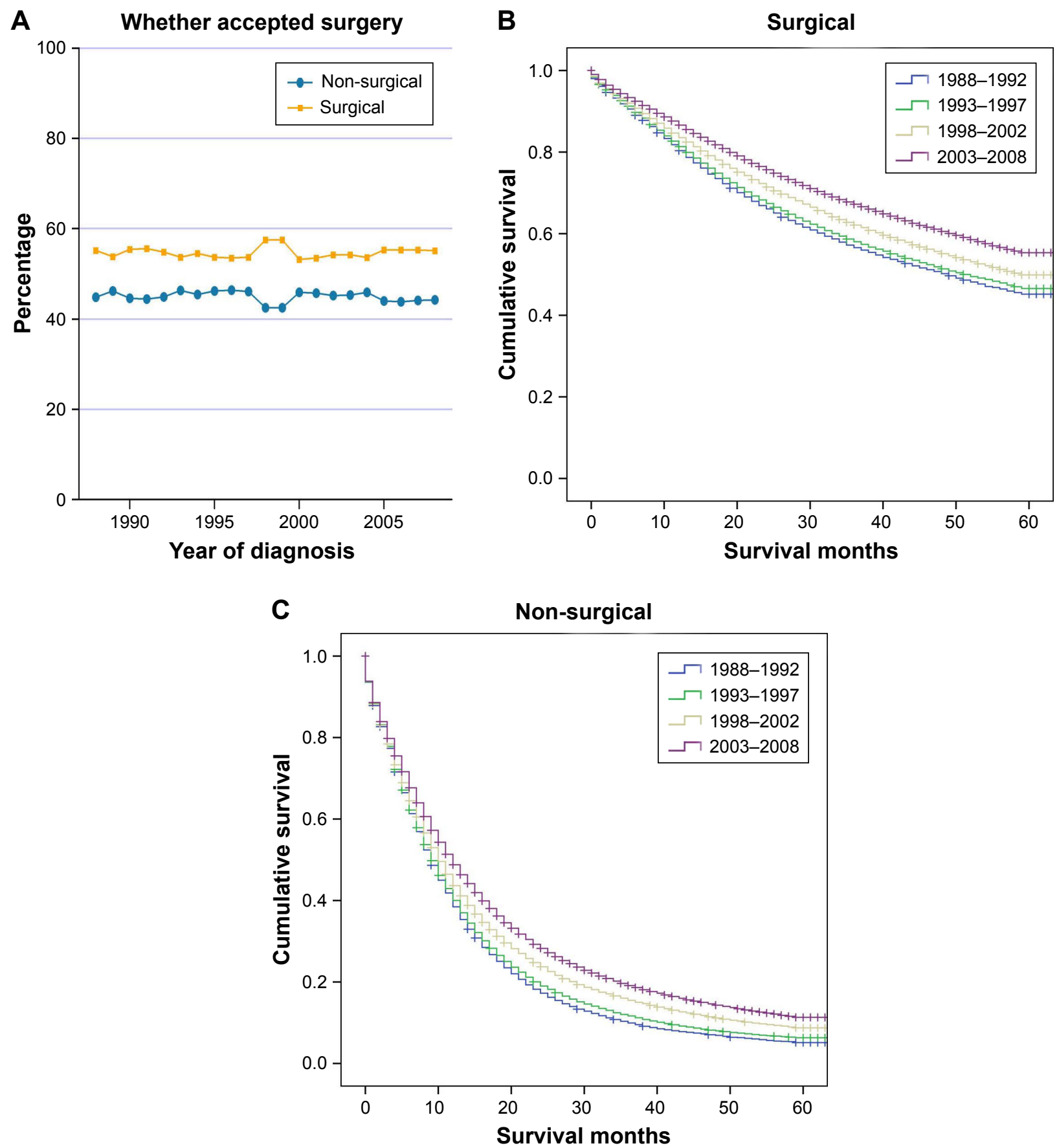

Figure 3 Trend of surgery rate (A) and Kaplan-Meier survival analysis for surgical (B) and non-surgical (C) groups. Cochran-Armitage trend test was used to evaluate trend $(\mathbf{A})$; all $P$-values $<0.001$.

of Thoracic Surgery (AATS), released guidelines with the recommendation that patients in the age range of 55-74 who have smoked at least 30 pack-years and current or former smokers with smoking cessation within 15 years were to receive annual LDCT. ${ }^{20-23}$ Along with the popularization of LDCT as a screening method, early screening may contribute greatly to the survival of patients with NSCLC in the near future.
Excluding the impact of early screening, it is certain that the improvement in survival is attributable to improved therapy and medical care for NSCLC. Based on our data, relatively greater gains in survival were observed in patients with localized and regional stage disease compared to patients with distant disease; however, considering the exciting advances during the past years in cancer research and care (angiogenesis inhibitors, molecular therapy, and 
A
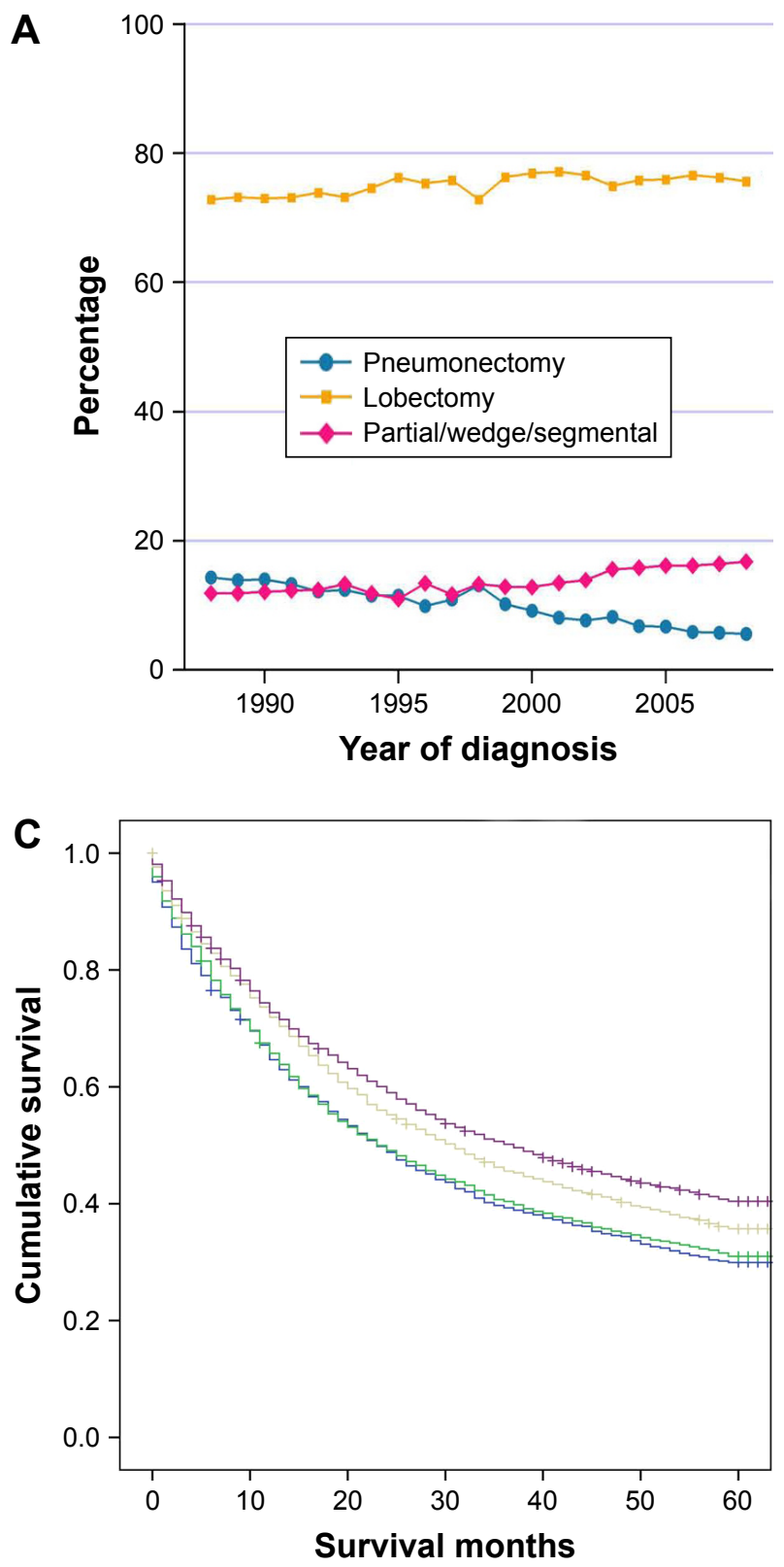

B
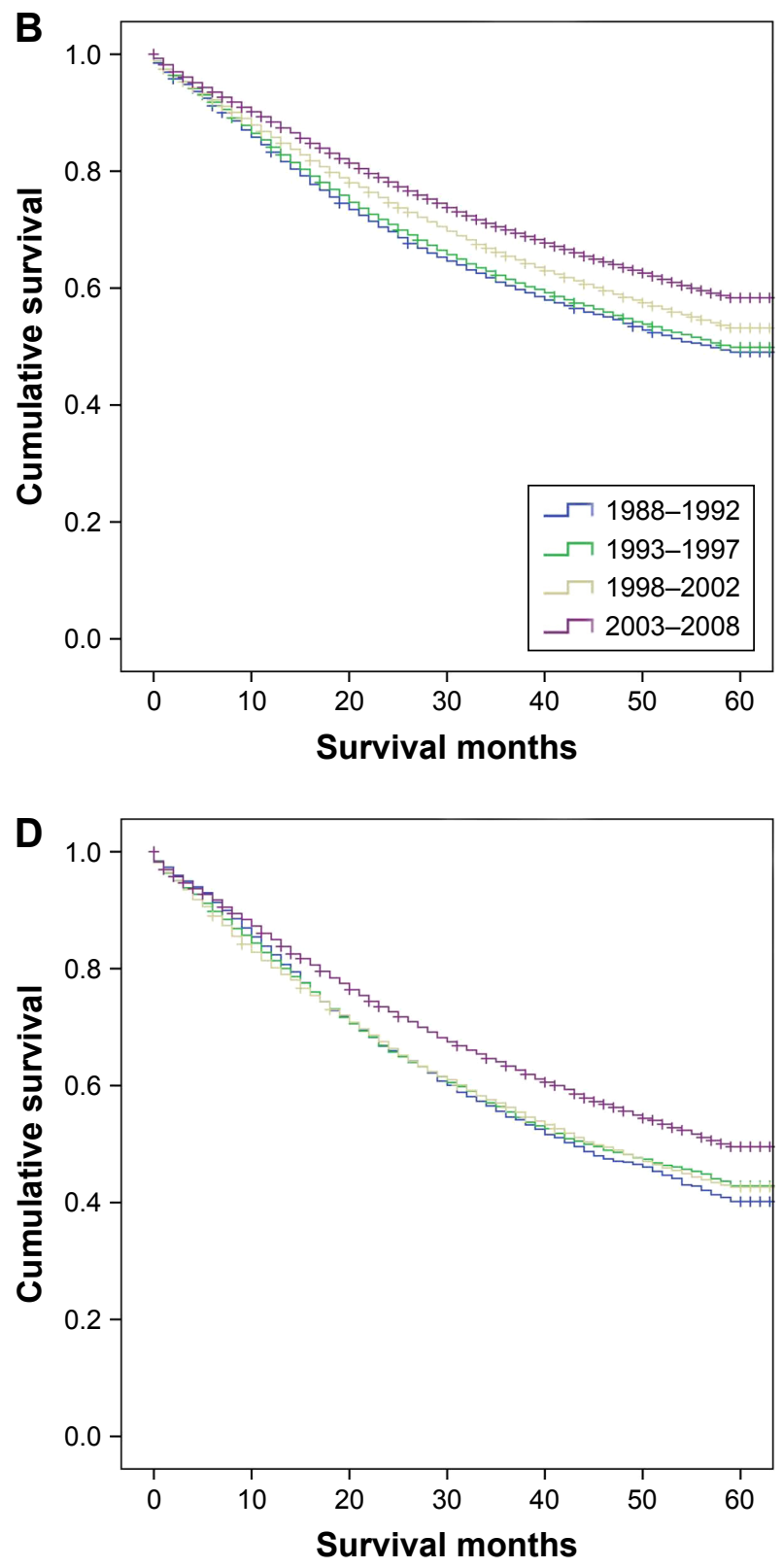

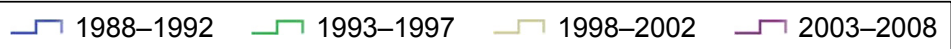

Figure 4 Trend of distribution of surgical approaches for NSCLC cases (A) and Kaplan-Meier survival analysis for specific surgical approaches (B) lobectomy, (C) pneumonectomy, and (D) partial/wedge/segmental resection. Cochran-Armitage trend test was used to evaluate trend $(\mathbf{A})$; all $P$-values $<0.00 \mathrm{I}$.

immunotherapy), it is conceivable that survival improvement for patients with distant disease have accelerated after 2008 and will continue to improve. ${ }^{24}$

Surgical resection has long been considered to provide the best chance of cure for patients with early-stage NSCLC. The present study showed significant survival improvements specific to each of the surgical approach embodied the progress of surgical techniques and perioperative managements. Recently, several reports are revisiting whether lobectomy is necessary for tumors smaller than $2 \mathrm{~cm}$ with no sign of lymph node metastasis ${ }^{25-27}$ However, according to the present study, lobectomy remains the most common and favorable surgical approach. Whether segmentectomy or wedge resection can adequately treat small, peripheral bronchoalveolar NSCLC so as to improve survival will not be definitively confirmed until a prospective randomized trial focuses on this issue.

It should be noted that, although we used a considerable sample size from the SEER registries - representing diverse characteristics over two decades to analyze trends in these measures and NSCLC survival rates - the study was limited 
by the fact that the data reflected only selected SEER areas and were not applicable to other geographic locations. In addition, as a retrospective study, unmeasured selection bias enters into the research inevitably and limits interpretation.

\section{Conclusion}

In summary, our SEER analysis demonstrated improvements in patients with all stages of NSCLC, with relatively more significant gains for the patients with localized and regional disease. Moreover, we demonstrated considerable increases in survivals for patients through major surgical approaches, and the improvements were mainly attributable to improved therapy and medical care for NSCLC. The progress of early screening in patients with NSCLC is debatable, but screening work is promising in view of the favorable results generated recently.

\section{Acknowledgments}

This research was supported by the National Natural Science Foundation of China (Nos 81372321, 81472702, 81501977, 81672294), Natural Science Foundation of Jiangsu Province (grant number: SBK016030028), and the Innovation Capability Development Project of Jiangsu Province (No BM2015004).

\section{Disclosure}

The authors report no conflicts of interest in this work.

\section{References}

1. Siegel RL, Miller KD, Jemal A. Cancer statistics, 2016. CA Cancer J Clin. 2016;66(1):7-30.

2. Subramanian J, Regenbogen T, Nagaraj G, et al. Review of ongoing clinical trials in non-small-cell lung cancer: a status report for 2012 from the ClinicalTrials.gov Web site. J Thorac Oncol. 2013;8(7):860-865.

3. Birkmeyer JD, Siewers AE, Finlayson EV, et al. Hospital volume and surgical mortality in the United States. $N$ Engl J Med. 2002;346(15): 1128-1137.

4. Smith DL, Elting LS, Learn PA, Raut CP, Mansfield PF. Factors influencing the volume-outcome relationship in gastrectomies: a population-based study. Ann Surg Oncol. 2007;14(6):1846-1852.

5. Bach PB, Cramer LD, Schrag D, Downey RJ, Gelfand SE, Begg CB. The influence of hospital volume on survival after resection for lung cancer. N Engl J Med. 2001;345(3):181-188.

6. Finlayson EV, Goodney PP, Birkmeyer JD. Hospital volume and operative mortality in cancer surgery: a national study. Arch Surg. 2003; 138(7):721-725; discussion 726.

7. National Lung Screening Trial Research Team; Aberle DR, Adams AM, Berg CD, et al. Reduced lung-cancer mortality with low-dose computed tomographic screening. N Engl J Med. 2011;365(5):395-409.

8. National Cancer Institute. Surveillance, epidemiology, and end results (SEER) program. Research data (1973-2013). Available from: www. seer.cancer.gov. Accessed May 15, 2017.
9. National Cancer Institute. Surveillance, epidemiology, and end results program. ICD-0-3 SEER Site/histology validation list. Available from: http://seer.cancer.gov/icd-o-3/. Accessed May 15, 2017.

10. Ahn HS, Kim HJ, Welch HG. Korea's thyroid-cancer "epidemic" screening and overdiagnosis. N Engl J Med. 2014;371(19):1765-1767.

11. Black WC, Welch HG. Advances in diagnostic imaging and overestimations of disease prevalence and the benefits of therapy. $N$ Engl J Med. 1993;328(17):1237-1243.

12. Fontana RS, Sanderson DR, Woolner LB, Taylor WF, Miller WE, Muhm JR. Lung cancer screening: the Mayo program. J Occup Med. 1986;28(8):746-750.

13. Fontana RS, Sanderson DR, Taylor WF, et al. Early lung cancer detection: results of the initial (prevalence) radiologic and cytologic screening in the Mayo Clinic study. Am Rev Respir Dis. 1984;130(4):561-565.

14. Melamed MR, Flehinger BJ, Zaman MB, Heelan RT, Perchick WA, Martini N. Screening for early lung cancer. Results of the Memorial Sloan-Kettering study in New York. Chest. 1984;86(1):44-53.

15. Kubík A, Polák J. Lung cancer detection. Results of a randomized prospective study in Czechoslovakia. Cancer. 1986;57(12):2427-2437.

16. Kubík A, Haerting J. Survival and mortality in a randomized study of lung cancer detection. Neoplasma. 1990;37(4):467-475.

17. Strauss GM, Gleason RE, Sugarbaker DJ. Chest X-ray screening improves outcome in lung cancer. A reappraisal of randomized trials on lung cancer screening. Chest. 1995;107(6 Suppl):270S-279S.

18. Moyer VA. Lung cancer prevention and screening. Oncology. 2014; 28(5):449-450.

19. Paci E. Observational, one-arm studies and randomized populationbased trials for evaluation of the efficacy of lung cancer screening. J Thorac Oncol. 2007;2(5 Suppl):S45-S46.

20. American Lung Association. Providing Guidance on lung cancer screening. The American Lung Association Interim Report on Lung Cancer Screening. Available from: http://www.lung.org/lung-disease/ lungcancer/lung-cancer-screening-guidelines/lung-cancer-screening. pdf. Accessed August 10, 2016

21. Wender R, Fontham ET, Barrera E Jr, et al. American Cancer Society lung cancer screening guidelines. CA Cancer J Clin. 2013;63(2): 107-117.

22. Bach PB, Mirkin JN, Oliver TK, et al. Benefits and harms of CT screening for lung cancer: a systematic review. JAMA. 2012;307(22): 2418-2429.

23. Jaklitsch MT, Jacobson FL, Austin JH, et al. The American Association for Thoracic Surgery guidelines for lung cancer screening using lowdose computed tomography scans for lung cancer survivors and other high-risk groups. J Thorac Cardiovasc Surg. 2012;144(1):33-38.

24. Mazières J, Peters S, Lepage B, et al. Lung cancer that harbors an HER2 mutation: epidemiologic characteristics and therapeutic perspectives. J Clin Oncol. 2013;31(16):1997-2003.

25. Miller DL, Rowland CM, Deschamps C, Allen MS, Trastek VF, Pairolero PC. Surgical treatment of non-small cell lung cancer $1 \mathrm{~cm}$ or less in diameter. Ann Thorac Surg. 2002;73(5):1545-1550; discussion 1550-1551.

26. Okada M, Nishio W, Sakamoto T, et al. Effect of tumor size on prognosis in patients with non-small cell lung cancer: the role of segmentectomy as a type of lesser resection. $J$ Thorac Cardiovasc Surg. 2005;129(1):87-93.

27. Yamato Y, Tsuchida M, Watanabe T, et al. Early results of a prospective study of limited resection for bronchioloalveolar adenocarcinoma of the lung. Ann Thorac Surg. 2001;71(3):971-974. 


\section{Publish your work in this journal}

OncoTargets and Therapy is an international, peer-reviewed, open access journal focusing on the pathological basis of all cancers, potential targets for therapy and treatment protocols employed to improve the management of cancer patients. The journal also focuses on the impact of management programs and new therapeutic agents and protocols on
Dovepress

patient perspectives such as quality of life, adherence and satisfaction. The manuscript management system is completely online and includes a very quick and fair peer-review system, which is all easy to use. Visit http://www.dovepress.com/testimonials.php to read real quotes from published authors.

Submit your manuscript here: http://www.dovepress.com/oncotargets-and-therapy-journal 